\title{
Runoff properties of extreme discharges on Paraná and Uruguay rivers
}

\author{
W. Vargas ${ }^{1}$, S. Bischoff ${ }^{2}$, G. Naumann ${ }^{1}$, and E. Marcuzzi ${ }^{3}$ \\ ${ }^{1}$ Consejo Nacional de Investigaciones Científicas y Técnicas (CONICET), Departamento de \\ Ciencias de la Atmósfera y los Océanos, Facultad de Ciencias Exactas y Naturales, \\ Universidad de Buenos Aires, Argentina \\ ${ }^{2}$ Servicio Meteorológico Nacional de Argentina, Buenos Aires, Argentina \\ ${ }^{3}$ Plan Nacional de Manejo del Fuego, Secretaria de Ambiente y desarrollo, Buenos Aires, \\ Argentina
}

Received: 28 April 2010 - Accepted: 5 May 2010 - Published: 12 May 2010

Correspondence to: Gustavo Naumann (gnaumann@at.fcen.uba.ar)

Published by Copernicus Publications on behalf of the European Geosciences Union.

\begin{abstract}
Climate variability in different spatial scales is a study area which has reached interest in application, especially during de last years. River discharges can be considered as a robust integrator of the properties of the basin; under these premises the goal of this 5 work is to analyse flows from the Paraná and Uruguay rivers in several gauge stations and study the behavior of positive and negative anomalies and their extremes. The variable to be analysed was defined as the number of anomalies with the same sign per year. Results show that the structures are different for both rivers, which implies a different stochastic process. Identical representativeness was found between the 10 anomaly series in each river. The risk estimation of extremes in both rivers indicates that it is possible to establish a decision model. Additionally, the series of annual number of anomalies presented a climatic jump in the seventies, for both rivers.
\end{abstract}

\section{Introduction}

Climate variability at different spatial scales is an area of study that has gained inter15 est especially within the last years. A way to measure the climate variability is from the runoff data, since it can be considered as a sound integrator of the properties of the drainage basin. (Rickey et al., 1989; Conway and Hulme, 1993). In particular, La Plata Basin covers about $3.2 \times 10^{6} \mathrm{~km}^{2}$ and the annual-mean discharge is about $21000 \mathrm{~m} \mathrm{~s}^{3} \mathrm{~s}^{-1}$ (Berbery and Barros, 2002). The basin spreads over five South Ameri-

20 can countries; approximately $46 \%$ of its surface is in Brazil, $30 \%$ in Argentina, $13 \%$ in Paraguay, $7 \%$ in Bolivia, and $4 \%$ in Uruguay.

Regarding temporal changes in the basin Garcia and Vargas $(1996,1998)$ show a change of tendency between 1970 and 1972, and another not so significant before that date were detected in 1917-1918 and 1943-1944. Also They showed jumps mainly in the period 1970-1972 in the annual streamflows series. In the other hand, Robertson and Mechoso (1998) have presented evidence that the streamflows of four major rivers 
in southeastern South America have interannual cycles (at about 3.5 and $6 \mathrm{yr}$ ), a neardecadal cycle with period of approximately $9 \mathrm{yr}$, as well as a nonlinear trend. Genta et al. (1998) demonstrate that the 30-yr running averaged streamflows increased after the mid-1960s at a rate that is approximately linear but not the same in all rivers. Also,

5 the increased streamflow is consistent with a significant decrease in the amplitude of the seasonal cycle in all rivers.

Analyzing interannual variability Camilloni and Barros (2000), Berri et al. (2002), Camilloni and Barros (2003) indicate that this kind of variability is linked with El Niño - Southern Oscillation (ENSO). Berbery and Barros (2002) shown that the historical 10 maxima of river discharge during the year following the onset of El Niño can triple the typical mean river discharge.

The aim of this paper is two-fold: on the one hand, to analyze the runoff series for Paraná and Uruguay rivers at several gauge stations, and to study the behavior of monthly negative as well as positive anomalies along with the frequency distribution of

15 the annual frequency for this anomalies, their extreme values, and the spells of extreme values in order to establish the presence of transference functions both for rainfall and discharge. On the other hand, to estimate the homogeneity and representativeness of the measurements for a single river at different gauge stations and for both rivers jointly were studied. Also that allows to assess on the joint risks for extreme anomalies

20 in runoff occurrence. A more general goal of this work is to diagnose extreme minimum and maximum runoff and their joint occurrence. An example of the potential relation between the functions of extreme runoff and precipitation can be found in Vargas and Bischoff (2000).

In this paper the compatibility of the models that adjust the properties of the monthly 25 rainfall and monthly streamflows are analyzed. Section 2 presents the methods and data used for the study. Monthly runoff anomalies frequency and extreme anomalies are presented in Sect. 3. Section 4 shows the spatial behavior of the entropy and evaluates the joint risk of extreme anomalies. The temporal variability of the monthly runoff are anomalies are presented in Sect. 5. Finally, Sect. 6 summarizes the main

2951

conclusions.

\section{Methodology and data management}

Data used consist in mean monthly flows, collected at four gauge stations in the Paraná River and other four in the Uruguay River. Gauge station information is shown in Ta5 ble 1. Data were provided by Water Resources Secretary (www.hidricosargentina.gov. ar). Besides, monthly precipitation data obtained by the National weather service of Argentina (SMN) was also used for the Paraná basin (see Table 2). Figure 1 shows the basins for both rivers and the position of the gauge stations.

Both for runoff and precipitation monthly anomalies were calculated. By this way the 10 most part of the influence of the annual wave was eliminated. Monthly positive (negative) anomalies are defined as positive (negative) values regarding monthly mean value. Extreme monthly positive (or negative) anomalies are defined as those anomalies included within the seventh to tenth (first to third) deciles. The variable to study is the frequency of same sign anomalies for any year. The spell of monthly anomalies is defined by the monthly sequence of anomalies with the same sign.

\section{Monthly runoff anomalies frequency per year}

For each gauge station the number of positive and negative anomalies per year was calculated separately. Figure 2 show the frequency distributions for the negative (positive) anomalies for both rivers. As shown in Fig. 2 it can be stated that the selected gauge stations for each river possess similar statistical structures in terms of the occurrence of both, positive and negative anomalies. Perhaps the exception is the Paraná Túnel gauge station where the yearly anomalies are lesser than in the other gauge stations. For monthly positive as well as negative anomalies it can be seen that Uruguay River show a very distinctive main maximum and two secondary maxima. Negative 
(positive) anomalies peak between July and September (March and July). As to the Paraná River, monthly anomalies frequency distributions don't have a main maximum, there is a maximum extended between April to December for negative anomalies and between January to August for positive anomalies although still two or three peaks with

5 similar frequency percentage can be observed. This imply different stochastic processes and different hydrological behavior for the runoff series of each river. Moreover, it is evident that the asymmetry of the monthly anomalies frequency distributions depends on whether the anomalies are positive or negative. Smaller frequencies for the lower (greater) values of negative (positive) anomalies can be found for both rivers. The

- presence of more than a single maximum in the runoff frequency distributions does not permit to adjust this distributions to a binomial one.

Another way to visualise the behaviour of the different gauge stations at each river is by means of the accumulated runoff monthly anomalies month by month. Figure 3 shows, for each gauge station, the sequence of accumulated monthly anomalies of 5 runoff during 1970-1971 and 1980-1981 for both rivers.

It can be seen from Fig. 3 that, although two particular periods are represented, all the gauge stations belonging to a river show similar characteristics and, at the same time, the functioning in each one of the rivers is different for a common period. In particular, it will be discussed the period 1970-1971. As for the Paraná River, the sequence

20 of negative anomalies dominate during the whole period. For the Uruguay River, the negative anomalies are present during 1970, then there is present an accumulation of runoff positive anomalies during nine months, and finally a rapid decrease in the last four months of the period takes place. This might indicate different weather impacts within a same scale of occurrence of precipitation at both basins.

25 Regarding monthly precipitation anomalies, the distribution shows a single maximum and fits well to a binomial distribution. Figure 4 shows the frequency distribution of positive and negative monthly anomaly precipitation at Posadas station, located in the Paraná basin. This station represents well the behavior of the other stations in the basin, since all of them adjust well to the same model. The presence of a single

2953

maximum in the precipitation frequency distribution permit to adjust this distributions to a binomial one.

The different models for adjusting the frequency distributions for precipitation and stream flow dificult the creation of an empirical model for the water balance.

\section{$5 \quad 3.1$ Extreme anomalies}

One might ask whether the frequency distributions stand for the extreme anomalies per year of runoff. Figure 5 show the frequency distributions for extreme runoff negative and positive monthly anomalies per year at (a) the Uruguay River and (b) the Paraná River. Compared with the empirical model that fits the distributions of runoff frequency anomalies distribution shown in Fig. 2 can be observed that for extreme anomalies it changes significantly. Extreme anomalies for both rivers are represented by a distribution showing an exponential decrease. Comparing the models for both rivers it can be seen that the runoff at any gauge station located in the Paraná River decrease more rapid than the runoff at any gauge stations located in the Uruguay River. Physically

15 this would indicate that all year long, the Paraná River possesses a major inertia to produce sequences of monthly anomalies of the same sign than the Uruguay River.

Results presented so far allow to figure out that the extreme anomalies at different gauge stations behave in the same way in terms of annual frequencies, implying that any gauge station can represent the runoff regime of each river.

\section{$20 \quad 3.2$ Spells for extreme monthly anomalies}

Spells were defined as the set of consecutive months in which runoff extreme anomalies keep sign. Following this definition, empirical runoff frequency distributions for extreme spells at all the gauge stations were found. Table 3 shows frequency and duration of extreme spells for the gauge stations located in both rivers. In terms of absolute

25 frequencies, there is a more rapid decrease for the 1- and 2-month sequences for the Paraná River than for Uruguay River. Besides, this stands for both signs of anomalies. 
This could be associated to different precipitation drainage processes for both rivers. In the case of the Paraná River this processes seems to be slower, even for intense rainfall associated to synoptic weather systems during several days within its basin, establishing differences in the number of monthly spells, in particular those associated

5 to 1 and 2 months. This is not the case for the Uruguay River since the draining processes for this river are very sensitive to precipitation associated with synoptic-scale weather systems, or even with shorter timescales.

Major duration for positive spells can be found in the Paraná River with one event of 16 consecutive months and can be identified at all the gauge stations simultaneously.

10 Particularly for the Uruguay River the maximum positive spell corresponds to 7 months, also identified at all the gauge stations. This entails an important difference regarding the behaviour of the two rivers. As to the negative spells, the long-lasted ones (those lasting at least 13 or 14 months) can be found at both rivers, although detected at isolated gauge stations. In summary, at least for both studied basin extreme positive

15 spells affect the river basin as a whole, while the extreme negative spells are more regional and cannot be extended to the whole basin. Finally, frequency distributions for the spells of extreme monthly anomalies are similar to the frequency distributions for extreme monthly anomalies per year. This would indicate that the monthly extreme anomalies have a high probability of occurring in one month

\section{Entropy and joint diagnosis}

To analyse persistence and to assess on the difficulties to forecast these individual events with a model, the randomness features for the monthly flow were also investigated in this research. This was done with the aid of the concept of entropy (Shannon, 1948). Entropy for a set $Z$ is defined as

$25 \mathrm{H}(\mathrm{Z})=\sum_{i} P\left(\mathrm{~A}_{i}\right) \ln P\left(\mathrm{~A}_{i}\right)$

where $A_{i}$ are disjoint events within the space of occurrence with probability

$P(\mathrm{~A} 1, \mathrm{~A} 2, \mathrm{~A} 3, \ldots, \mathrm{A} r)=1$

$H(Z)$ measures randomness for the individual random events. From Eq. (1) it can be seen that the highest amount of uncertainty from an information source is realized 5 when the output symbols of the source are equally probable. The entropy varies from 0 to $\log (\mathrm{m})$, so the entropy may be standardized such that it would range from 0 to 1 by dividing it by its maximum.

In this case, the individual events are the monthly flows. Table 4 show entropy for the gauge stations at both rivers. Greater entropy corresponds to $\mathrm{CR}$, located northeast

10 of Argentina, in the confluence of Paraná and Paraguay rivers. Comparing the results presented in Table 4 it can be seen that the Uruguay River presents higher values of entropy for all the gauge stations, indicating a greater variability in the monthly flows. This means that if an adjustment of a forecast model to the Uruguay River monthly flows is intended, it requires more information and a much more complex model.

\section{4.1 Analysis of the partial spatial coherence}

In order to complete the verification of the homogeneity of the anomalies structure for each river and to consider the spatial and temporal coherence, the correlations between the series of monthly anomalies of runoff were calculated. Tables 5 and 6 show cross-correlations for the time series of monthly anomalies between the gauge 20 stations in the Uruguay and Paraná rivers.

Despite all the correlations are significant, these are greater for the Uruguay River. In other words, this imply a greater homogeneity for the monthly runoff anomalies in the Uruguay River, a fact that can be due to the greater number of tributaries Paraná River has, many of them affected by different regimes. Under the light of the results 25 presented here the time series from any gauge station represents well the behavior of the anomalies for the whole river basin. 


\subsection{Joint risk of monthly extreme anomalies}

In order to estimate the joint risk of anomalies for extreme runoff - necessary for operation, modification, and construction of water resources decision models -, the joint probability of monthly deficit and monthly excesses occurrences for a variable number

5 of stations $(0,1,2,3,4)$ between the rivers. Tables 7 and 8 show the frequencies of the relationship between minimum and maximum flows.

After analyzing the joint probability for minimum runoff shown in Table 7, it can be stressed the low probability to have joint occurrence of minima, even when the quantity of gauge stations is discriminated. It can be highlighted, however, that probabilities exceeding $10 \%$ are associated to the absence of minima in the Uruguay River, and to minima in one and three gauge stations located in the Paraná River. On the other hand the absence of minima in the Paraná River flow and minimum flow at the four gauge stations in the Uruguay River are an important feature. As to minima flow this might indicate that higher probabilities of joint occurrence are likely to take place for opposite

15 conditions in both river flows. Concerning the probability of joint occurrence for the positive extremes, as shown in Table 8, it can be seen again that the higher values are in correspondence with opposite conditions. These results indicate that both rivers are in opposite conditions, regardless the condition of the flows. As a consequence, forecast models and diagnostics should contemplate more than a single version for a 20 single basin (River Plate basin in this research).

\section{Temporal variability for the annual frequencies of positive anomalies}

Among the most important variability for these river basins are the low frequency ones, which can be distinguished from the runoff and precipitation time series. Figure 6 show the annual variation of monthly positive flow anomalies per year in the Uruguay River,

25 in the Paraná River, and for the annual precipitation at Paraná station, respectively. The well known climatic jump that took place near 1970 (Garcia and Vargas, 1998)

is clearly present in the Paraná River (Fig. 6b) and in the rainfall anomalies at Paraná (Fig. 6c). As a consequence of this, in many cases the estimation of the trends in these long time series results in an increase of runoff and precipitation for this region.

\section{Conclusions}

5 It has been shown in this research that the gauge stations for the Uruguay and Paraná rivers are coherent-behaved, even for the behavior of the extreme events, as it was analyzed. Therefore, a model of synthesis samples and/or series of stream flow can be representative of the river basin using the information of a single station. An exception to this could be the Túnel gauge station, in the Paraná River. The structure of the 10 properties of the studied anomalies of any sign shows different regimes in both rivers. In addition, the asymmetry in the distributions indicates that the number of positive and negative anomalies per year present frequencies that are inverted for the low values ( 1 to 3 months) and for the high values (10 to 12 months). However, when the studied properties refer to extreme anomalies, both rivers present the same type of distribution

15 (exponential decrease); by the way, it is identical to the spell anomalies distribution (not shown here). This implies that both rivers would have the same climatic regime for the extreme anomalies. This Climatic scale in this case would be greater than the area of each river basin or would include them altogether. Yet, the analysis of simultaneous minimum (or maximum) flows shows that it is likely to have such an event in one river

20 basin but not in the other, confirming that dominant processes in river basins are not always rising from the same scale. Concerning low frequencies, both rivers show a jump by 1970 s, a fact that is also confirmed using precipitation data from a station that represents well many aspects for both river basins.

Acknowledgements. This work was funded by projects UBA X-228, BID 1728/OC-AR and 25 CONICET PIP 112-200801-00762. 


\section{References}

Berbery, E. H. and Barros, V. R.: The hydrologic cycle of the La Plata basin in South America, J. Hydrometeor., 3, 630-645, 2002.

Berri, G. S., Ghietto, M. A., and García, N. O.: The influence of ENSO in the flows of the Upper Paraná River of South America over the past 100 years, J. Hydrometeor, 3, 57-65, 2002.

Camilloni, I. and Barros, V. R.: The Paraná River response to El Niño 1982-83 and 1997-98 events, J. Hydrometeor., 1, 412-430, 2000.

Camilloni, I. and Barros, V.: Extreme discharge events in the Paraná River and their climate forcing, J. Hydrol., 278, 94-109, 2003.

10 Conway, D. and Hulme, M.: Recent fluctuations in precipitation and runoff over the Nile subbasins and their impact on main Nile discharge, Climatic Change, 25, 127-151, 1993.

García, N. O. and Vargas, W. M. : The Temporal Climatic Variability in the "Río De La Plata" Basin Displayed by the River Discharges, Climatic Change, 38, 359-379, 1988.

Garcia, N. O. and Vargas, W. M.: The spatial variability of runoff and precipitation in the Rio de la Plata basin, Hydrolog. Sci. J., 41(3), 279-299, 1996.

Genta, J. L., Perez-Iribarren, G., and Mechoso, C. R.: A recent increasing trend in the streamflow of rivers in southeastern South America, J. Climate, 11, 2858-2862, 1998.

Rickey, J. E., Nobre, C. and Deser, C.: Amazon river discharge and climate variability: 19031985, Science, 246, 101-103, 1989.

20 Robertson, A W. and Mechoso, C. R.: Interannual and decadal cycles in river flows of southeastern South America, J. Clim., 11, 2570-2581, 1998.

Shannon, C. E.: A mathematical theory of communication, Bell Syst. Tech. J., 27, 379-423, 623-656, 1948.

Vargas W. M. and Bischoff, S.: Comparison between the statistical structures of rainfalls and volumes of the Uruguay River basin. XI Congreso Brasileiro de Meteorologia, Río de Janeiro, Brasil, 2000.

Table 1. Gauge stations of Uruguay and Paraná rivers.

\begin{tabular}{clcllll}
\hline Code & Gauge station & Abbreviation & River & Period & Latitude & Longitude \\
\hline 1 & Santo Tomé & ST & Uruguay & $1908-1998$ & -28.50 & -56.01 \\
2 & Monte Caseros & MC & Uruguay & $1908-1989$ & -30.25 & -57.63 \\
3 & Paso de los Libres & PL & Uruguay & $1908-1988$ & -29.72 & -57.07 \\
4 & Concordia & CO & Uruguay & $1898-1998$ & -31.30 & -58.01 \\
5 & Posadas & PO & Paraná & $1901-1990$ & -27.37 & -55.97 \\
6 & Itatí & IT & Paraná & $1911-2000$ & -27.28 & -58.24 \\
7 & Corrientes & CR & Paraná & $1904-2000$ & -27.45 & -58.82 \\
8 & Paraná Túnel & TU & Paraná & $1904-1994$ & -31.70 & -60.51 \\
\hline
\end{tabular}


Table 2. Posadas precipitation station.

\begin{tabular}{lccccc}
\hline Station & Abbreviation & start year & end year & Latitude & Longitude \\
\hline Posadas & PO & 1901 & 1991 & -27.22 & -55.58 \\
\hline
\end{tabular}

Table 3. Frequency and duration of extreme (a) Negative and (b) Positive monthly anomalies spells at the eight Paraná and Uruguay rivers gauge stations.

\begin{tabular}{|c|c|c|c|c|c|c|c|c|c|}
\hline \multicolumn{2}{|c|}{ DURATION } & \multirow[b]{2}{*}{ Itati } & \multicolumn{7}{|c|}{ Extreme Positive Spells (1911-1989) } \\
\hline (MONTHS) & Túnel & & Itacua & Corrientes & Posadas & S. Tomé & Paso & Concordia & Caseros \\
\hline 1 & 739 & 645 & 746 & 736 & 716 & 696 & 685 & 704 & 695 \\
\hline 2 & 21 & 29 & 36 & 22 & 34 & 48 & 38 & 39 & 45 \\
\hline 3 & 16 & 16 & 17 & 20 & 16 & 18 & 25 & 26 & 21 \\
\hline 4 & 15 & 8 & 9 & 15 & 11 & 11 & 10 & 8 & 7 \\
\hline 5 & 2 & 4 & 3 & 4 & 7 & 1 & 2 & 2 & 3 \\
\hline 6 & 3 & - & 2 & - & 1 & 1 & 1 & 4 & 1 \\
\hline 7 & 1 & - & 1 & - & 2 & 2 & 2 & 2 & 3 \\
\hline 8 & - & 1 & - & 1 & 1 & 2 & 1 & - & - \\
\hline 9 & - & - & - & 1 & - & 2 & 2 & 1 & 2 \\
\hline 10 & - & 2 & 1 & - & 1 & - & - & - & - \\
\hline 11 & 1 & - & - & - & - & - & - & - & - \\
\hline 12 & - & - & - & 1 & - & - & - & - & - \\
\hline 13 & - & - & - & - & - & - & - & - & 1 \\
\hline 14 & 1 & - & - & - & - & - & - & - & - \\
\hline 1 & 774 & 648 & 790 & 781 & 784 & 777 & 757 & 775 & 758 \\
\hline 2 & 20 & 29 & 36 & 26 & 36 & 43 & 44 & 43 & 44 \\
\hline 3 & 6 & 9 & 11 & 11 & 10 & 16 & 18 & 18 & 19 \\
\hline 4 & 11 & 9 & 2 & 7 & 3 & 4 & 4 & 4 & 6 \\
\hline 5 & 5 & 5 & 6 & 3 & 7 & 3 & 2 & 1 & 3 \\
\hline 6 & 3 & 1 & - & 4 & - & - & - & 1 & - \\
\hline 7 & 2 & 1 & - & - & - & 1 & 1 & 1 & 1 \\
\hline 8 & - & 1 & - & - & - & - & - & - & - \\
\hline 9 & - & - & - & - & - & - & - & - & - \\
\hline 10 & - & - & - & - & - & - & - & - & - \\
\hline 11 & - & - & - & - & - & - & - & - & - \\
\hline 12 & - & - & - & - & - & - & - & - & - \\
\hline 13 & - & - & - & - & - & - & - & - & - \\
\hline 14 & - & - & - & - & - & - & - & - & - \\
\hline 15 & - & - & - & - & - & - & - & - & - \\
\hline 16 & 1 & 1 & 1 & 1 & 1 & - & - & - & - \\
\hline
\end{tabular}


Table 4. Entropy calculated according Eq. (1) at each of the gauge stations.

\begin{tabular}{ccccc}
\hline \multicolumn{5}{c}{ Paraná River } \\
\hline IT & PO & IT & CR & TU \\
1.64 & 1.65 & 1.48 & 2.14 & 1.82 \\
\multicolumn{5}{c}{ Uruguay River } \\
\hline ST & MC & CO & PL \\
2.18 & 2.78 & 2.76 & 2.67 \\
\hline
\end{tabular}

\section{3}

Table 5. Cross-correlations for the time series of anomalies between the gauge stations of the Uruguay river. The colored values are significant at $5 \%$.

\begin{tabular}{ccccc}
\hline & ST & MC & PL & CO \\
\hline ST & 1.00 & 0.91 & 0.95 & 0.89 \\
MC & 0.91 & 1.00 & 0.98 & 0.98 \\
PL & 0.95 & 0.98 & 1.00 & 0.97 \\
CO & 0.89 & 0.98 & 0.97 & 1.00 \\
\hline
\end{tabular}


Table 6. As in Table 4 but for the Paraná river. Colored values are significant at $5 \%$.

\begin{tabular}{ccccc}
\hline & PO & IT & CR & TU \\
\hline PO & 1.00 & 0.83 & 0.93 & 0.75 \\
IT & 0.83 & 1.00 & 0.84 & 0.79 \\
CR & 0.93 & 0.84 & 1.00 & 0.89 \\
TU & 0.75 & 0.79 & 0.89 & 1.00 \\
\hline
\end{tabular}

\section{5}

Table 7. Joint frequency for Minimum runoff between stream water gauge stations in both rivers in percentage for 0 to 4 . Grey cells indicate joint probabilities greater than $10 \%$.

\begin{tabular}{|c|c|c|c|c|c|c|}
\hline & \multirow[b]{2}{*}{ Gauge station } & \multicolumn{5}{|c|}{ Uruguay } \\
\hline & & 0 & 1 & 2 & 3 & 4 \\
\hline \multirow{6}{*}{ 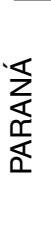 } & 0 & & 9.7 & 3.0 & 4.0 & 12.0 \\
\hline & 1 & 10.4 & 0.3 & 0.3 & 1.0 & 3.0 \\
\hline & 2 & 9.0 & 0.7 & 0.7 & 1.3 & 1.0 \\
\hline & 3 & 9.4 & 1.7 & 0.3 & 0.3 & 4.3 \\
\hline & 4 & 15.4 & 1.3 & 1.0 & 1.0 & 8.7 \\
\hline & & & & \multicolumn{3}{|c|}{299 months } \\
\hline
\end{tabular}


Table 8. Joint frequency for Maximum runoff between stream water gauge stations in both rivers in percentage for 0 to 4 . Grey cells indicates joint probabilities greater than $10 \%$.

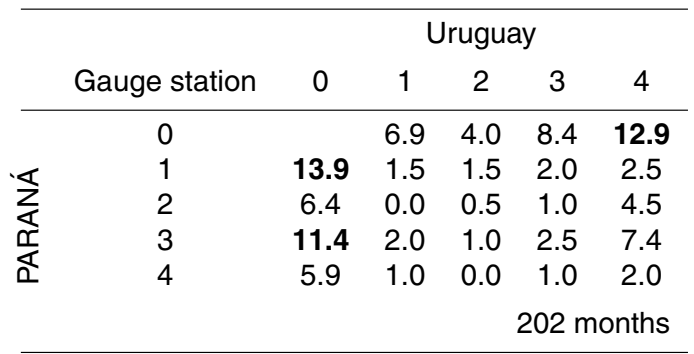

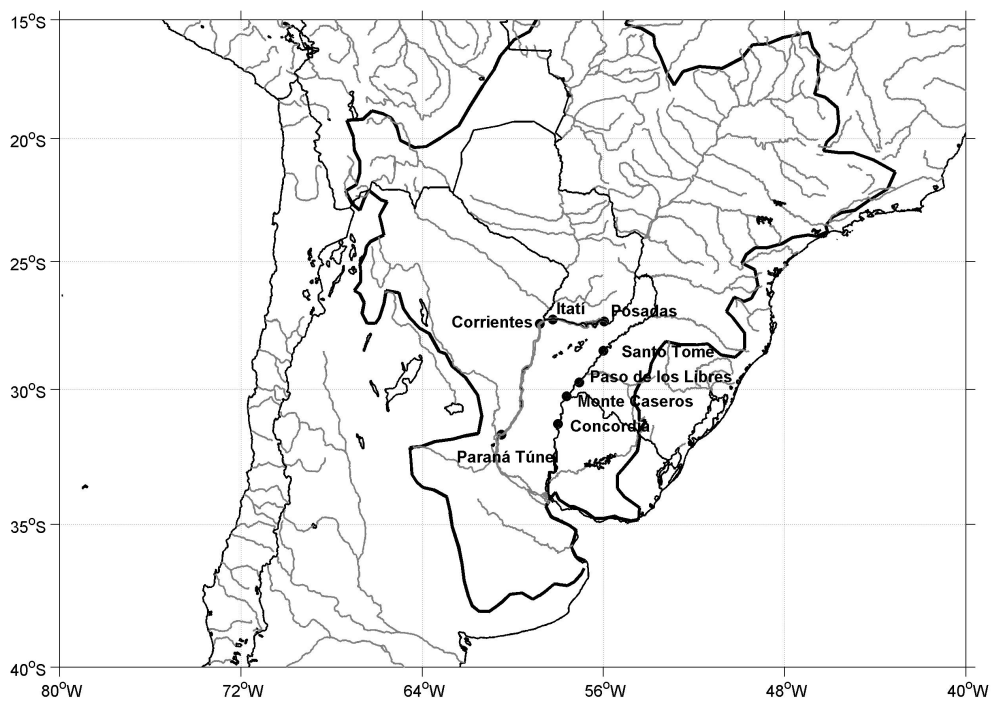

Fig. 1. La Plata Basin and the position of the gauge stations for both rivers according to code at Table 1. 

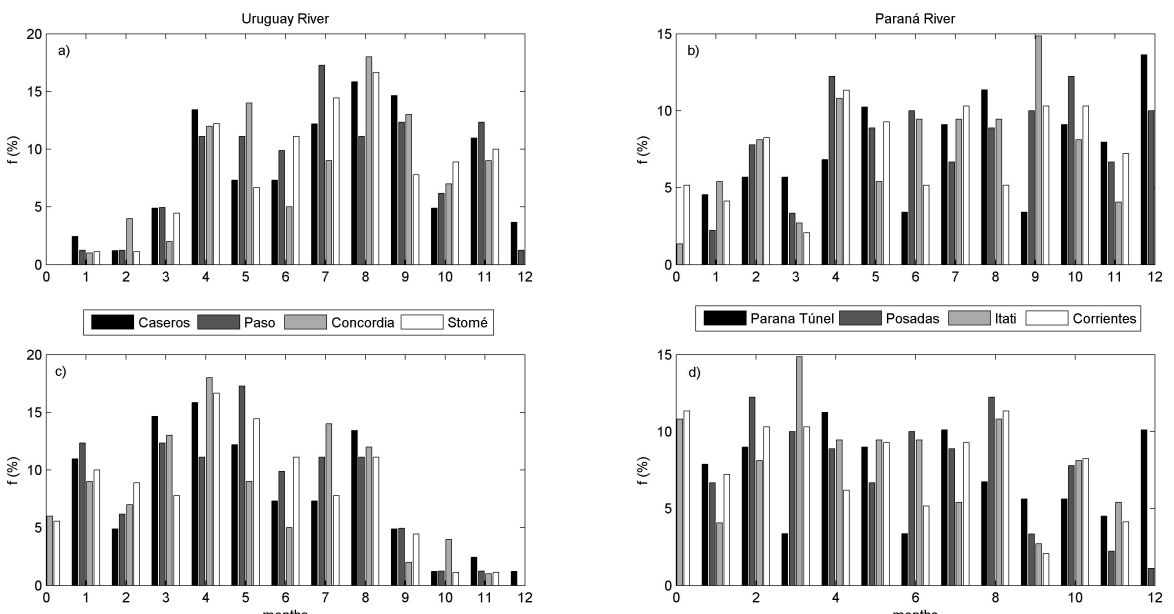

Fig. 2. Frequency percentage for the negative yearly anomalies (upper panel) and positive anomalies (lower panel) in Uruguay River (a), (c) and Paraná River (b), (d).
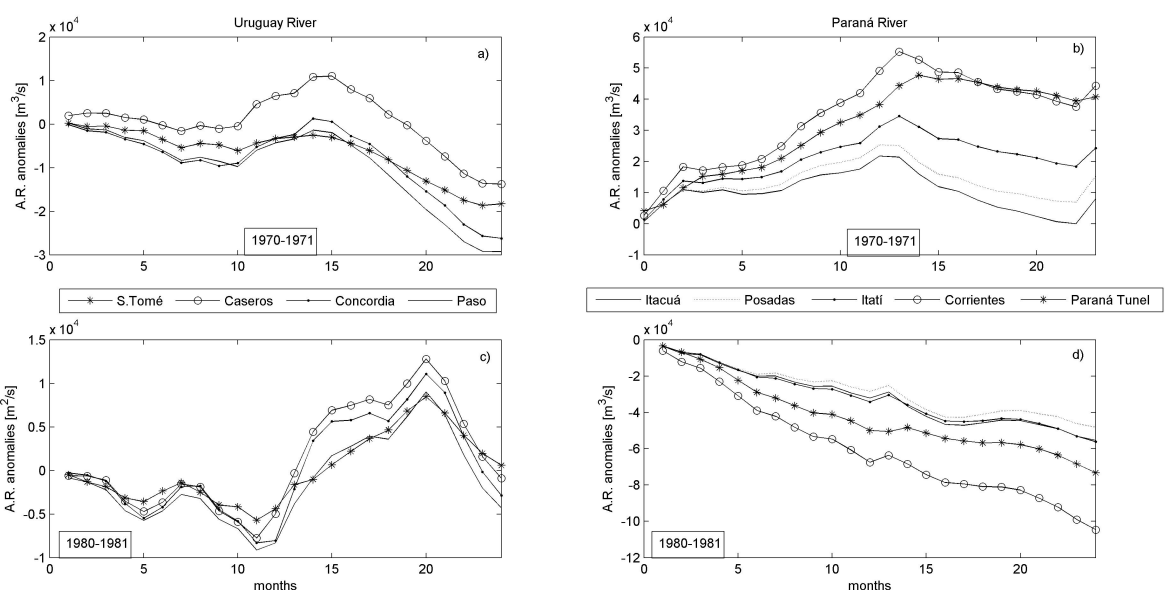

Fig. 3. Accumulated runoff monthly anomalies during 1970-1971 period (upper panel) and 1980-1981 period (lower panel) at Uruguay River (a), (c) and Paraná River (b), (d). 


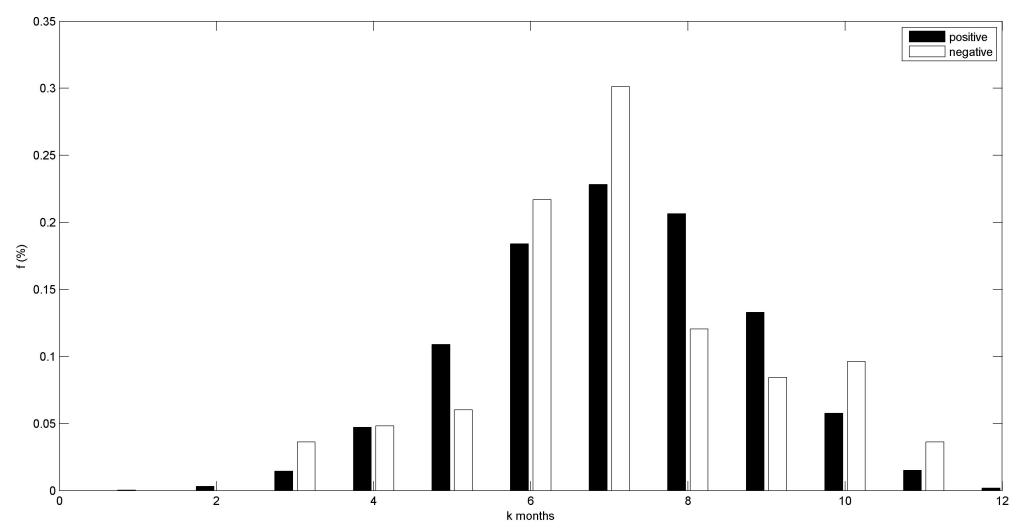

Fig. 4. Relative frequency distribution of positive (black) and negative (white) monthly anomaly precipitation at Posadas station, located in the Paraná River.
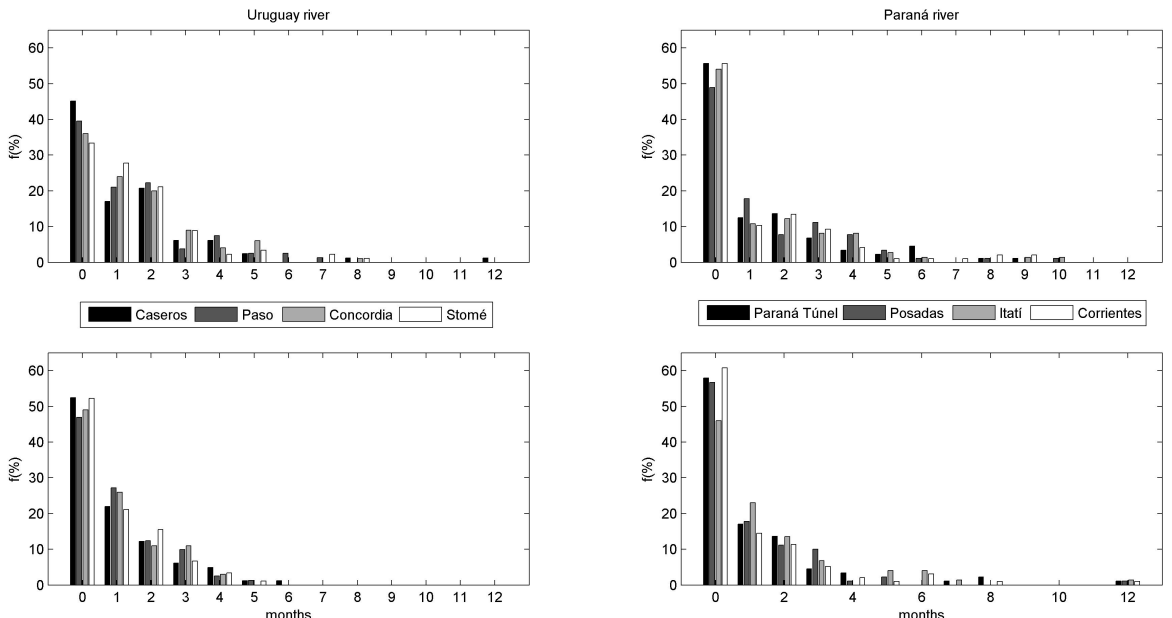

Fig. 5. Frequency in percentage of negative (upper panel) and positive (lower panel) extreme anomalies per year in the Uruguay River (left panel) and Paraná River (right panel). 

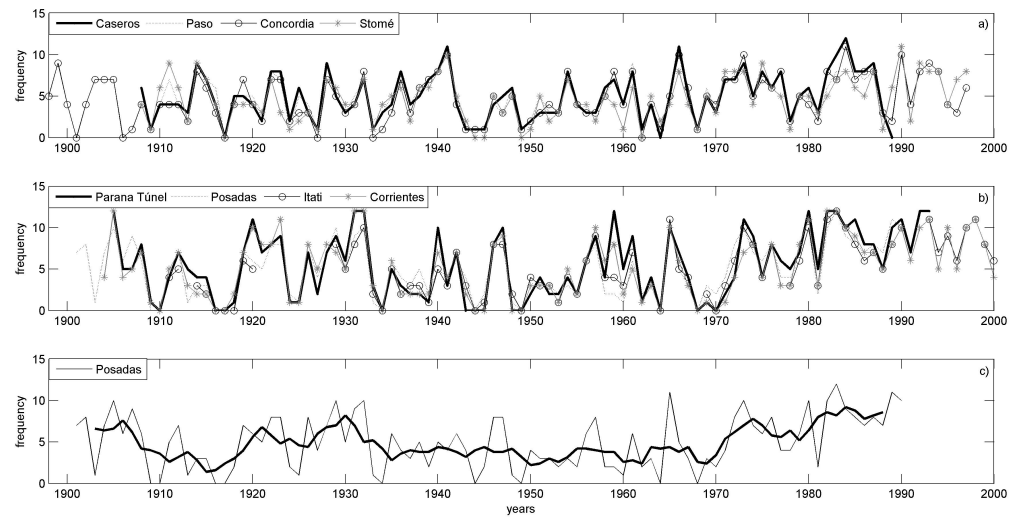

Fig. 6. Interannual variability of the positive anomalies frequency of runoff at Uruguay River (a), Paraná River (b) and positive precipitation anomalies frequency and moving average at Posadas station (c). 